\title{
Comparison of four microfinance markets from the point of view of the effectuation theory, complemented by proposed musketeer principle illustrating forces within village banks
}

\author{
Tomáš HES \\ Czech University of Life Sciences Prague, Prague, Czech Republic \\ hest@ftz.czu.cz \\ Haiyan SULAIMAN \\ Czech University of Life Sciences Prague, Prague, Czech Republic \\ Guillermo BALI CHÁVEZ \\ Comisión Nacional Para El Desarrollo De Los Pueblos Indígenas, Mexico City, Mexico \\ Samuel MINTAH \\ Czech University of Life Sciences Prague, Prague, Czech Republic
}

\author{
Ali SALMAN \\ Syrian Virtual University, Damascus, Syrian Arab Republic
}

\begin{abstract}
Microfinance services are essential tools of formalization of shadow economics, leveraging immature entrepreneurship with external capital. Given the importance of shadow economics for the social balance of developing countries, the importance of an answer to a question of how microfinance entities come into existence, is rather essential. While decision-taking process leading to entrepreneurship were explained by the effectuation theory developed in the 90's, these explanations were not concerned with the logics of creation of microenterprises in neither developing countries nor microfinance village banks. While the abovementioned theories explain the nascence of companies in environment of developed markets, importance of a focus on emerging markets related to large share of human society of microfinance clientele is obvious. The study provides a development streak to the effectuation Theory, adding the musketeer principle to the five effectuation principles proposed by Sarasvathy. Furthermore, the hitherto not considered relationship between social capital and effectuation related concepts is another proposal of the paper focusing on description of the nature of microfinance clientele from the point of view of effectuation theory and social capital drawing a comparison of microfinance markets in four countries, Turkey, Sierra Leone, Indonesia and Afghanistan.
\end{abstract}

Keywords: informal economics, village banks, SME, business, effectuation theory.

Please cite the article as follows: Hes, T., Sulaiman, H., Bali Chavez, G., Mintah, S. and Salman, A. (2017), "Comparison of four microfinance markets from the point of view of the effectuation theory, complemented by proposed musketeer principle illustrating forces within village banks", Management \& Marketing. Challenges for Knowledge Society, Vol. 12, No. 1, pp. 37-48. DOI: 10.1515/mmcks-2017-0003

\section{Introduction}

The decision process employed by employees and managers differs from the decision process employed by entrepreneurs (Sarasvathy, 2001). Understanding of this process can shed light on the decision taking principles leading to formation of enterprises. The effectuation theory, created in the 90s, belongs to methods solving problems of new enterprises, which are situations impacted by Knightian uncertainty (Knight, 1921), 
Weickian enactment (Weick, 1979) and Marchian goal ambiguity (March, 1982) having a say in unstructured spaces where predictability, independence of the environment and pre-existent goals are not available to decision makers (Wiltbank, 2010). Effectuation exists in parallel with predictive rationality, not negating rationality or irrationality and not being a random process, rather defining a constrained and a structured creativity process, denominating the prioritization as well as strategies undertaken by creators.

Its explanatory capacity transcends entrepreneurship, as this theory is an integratory attempt for structuration of basic principles of decision taking and integrating Rational Choice based theories although denoting rational choice based deviations. It therefore provides its own model with bounded problem space, being a partial solution integrated into a vision of a complete solution. While effectuation theory could possibly serve as a robust theoretical framework which can be used for empirical studies of decision making on entrepreneurial level (Wiltbank et al., 2010), this view of entrepreneurship is rather incomplete when dealing with microenterpreneurs in developing countries constituting the bulk of the microfinance clientele.

Microfinance entrepreneurship is different from the entrepreneurship studied by the authors of the effectuation theory due to the emerging market constraints with a high share of unstructured environment with immature societal infrastructures, such as legal frameworks or financial regulations. Also, microfinance entrepreneurship formed in village banks groups, with a strong influence of collective decision taking, entails a powerful component of informal social capital. The comprehension of decision taking process in minds of the microfinance entrepreneurs is however essential for the understanding of development economies, given the sheer number of potential microcredit clientele estimated at 975 million (Hes et al., 2003), underlined by the importance of informal employment reaching up to three quarters of non-agricultural employment in emerging markets (ILO, 2009 - OECD records 1.8 billion works in the informal economy vs. 1.2 billion in the formal sector).

\section{Effectuation and causation}

The concept of effectuation-causation tries to answer the question on what makes entrepreneurs entrepreneurial. While first theories postulated that entrepreneurs had specific genetic qualities including personality traits with risk-seeking character (Schumpeter, 1976), other theories explained entrepreneurship through opportunities offered by market inefficiencies, regulatory framework niche areas or leaps of breakthrough information. Sarasvathy in 2001 claimed that experts on management as well as economic theories actually assume that markets as well as organisations are not systems that exist as given per se, while any explanation on how they were created was not available. Effectuation theories based on the logics of control and prediction are notions explaining how entrepreneurs make decisions and thus make enterprises appear. According to Sarasvathy (2001), it is the effectuation principle that makes entrepreneurs grasp ideas related to services and products which are to be transformed into ready-made processes and being the principle behind stakeholder commitments, making entrepreneurs interact with correct partners and influencing decisions, being a one of the underlying reasons for the employment of techniques serving as a foundation. According to Chandler (2012), the five key principles of the effectuation framework are as follows: 
A Bird in Hand: starts with a simple definition of the means available only from gradually applying more creative contexts.

Affordable Loss: meaning limiting risks by focusing only on understanding of what could be afforded instead of permitting all-or-nothing risks.

Lemonade: This is a surprise factor or leveraging contingencies, which describes permit interpretation of unexpected news or surprising information sources as clues for opportunities.

Pilot-in-the Plane: This focuses on activities that are within the control of the entrepreneurs guiding future creation.

Patchwork Quilt: The partnerships with self-selected stakeholders permit reduction of risk through obtained pre-commitments.

The sum of these principles permits understanding of how to mitigate risks of the unknown and unpredictable future and how uncertainty is structured into a cognizant process describing the landscape of reality to be seized by conscious algorithm. While causation is considered by the approaches of planned strategies, which include the process of recognised opportunities as well as developing business plans, the concept of effectuation on the other hand provides emerging strategies that are consistent with the selection of alternative scenarios of future evolution, founded on the concepts of loss affordability and flexibility as well as experimentation. The effectuation logics, is the logics used by expert entrepreneurs, differing from causational logic, which is predominantly usually employed by managers and employees. The concept of the "effectual" can be considered the inverse concept of the "causal", predictive reasoning based on the vision of causal rationality, beginning with pre-determined goals as well as with given sets of means in the attempt to find the optimal and most efficient solutions to achieve given goals, while Effectual reasoning, is not tied to a specific aim (Sarasvathy, 2001).

It is instead related to a certain set of means, allowing aims to be created during the process as new ideas, inspirations and aspirations of the entrepreneur's success. Causal thinkers can be considered those who act as if they were conquering a known terrain, while effectual thinkers, on the other hand, could be considered explorers who are discovering new areas. One decision maker can, however, make use of both approaches, as well as of effectual and causal reasoning, depending on the circumstances. The best entrepreneurs are expected to make use of both strategies in parallel, while seemingly making use of effectual reasoning in the first part of the project over a causal reasoning concept in the latter part of the venture evolution (Sarasvathy, 2001). The creation of village banks however, being the basic credit related pillars of microfinance institutions, combines the two approaches, as the village bank formation and continuity requires individualist entrepreneurship as well as a team work with other village bank members bound by a shared debt burden and secured by solidarity guarantee.

\section{Social capital}

Social capital in any society can be seen in different dimensions such as groups and networks existing in the society which promote and protect relationships and improve welfare, trust and solidarity which foster greater cohesion and willingness to take initiative in social context based on the assumption that others will respond as expected, collective action and cooperation which foster the abilities of people to work together towards resolving community/social issues, social cohesion and inclusion which 
mitigates the risk of conflict and promotes equitable access to benefits of development by enhancing participation of the marginalized and lastly information and communication which provide improved access to information via network. The concept of social capital is a prominent theoretical innovation of the past two decades (Isham et al., 2002). Clarification of many of the connotations of the concept is however still a clear necessity (Grootaert et al., 2003), even two decades after its implementation. Although there exist many tools that are supposed to measure social capital in developing countries, the debate still develops in an empirical vacuum. Putnam et al. (1993) view social capital as a feature of social organizations, including trust, networks and norms that lead to improvement of functioning of groups or societies by facilitating coordination. Coleman (1988) sees social capital as assets within relationships facilitating instrumental action among humans, and capacity of sharing of resources ad well as knowledge.

ILO (2009) defines social capital as a set of norms and networks enabling action, including quality and quantity of social interactions. As far as microfinance is concerned, social capital is a condition and a key component to microfinance operations: whether for its sustainable success or its impact. Trust can be regarded as the acceptance of norms of others or norms of whole communities and rejection of incompatible norms (Bowles et al., 2002). Structural social capital is characterized by visible information sharing, collective action as well as decision making through structures of roles, habits, networks and procedures, rules and precedents, while cognitive social capital includes values, shared norms, trusts, attitudes and beliefs (Grootaert et al., 2001). Synergy of both capitals leads to increase of cooperation, problem solving, innovation transfer, reduction of information transfer costs and leads to creation of safety networks (Narayan, 1999) and represents infrastructures, comparable to formal infrastructures in formal financial systems, such as legal frameworks grids, SWIFT networks or ISO standards. This view can be therefore also applied on social finance as the pool of social capital becomes a conduct for information, permitting social capital to permeate financial capital.

\section{Microfinance, effectuation and social capital}

Microfinance entities bank on existing cultural platforms and shared values, enrich them through their educational component, become precursors for changes on macro level, and transform social capital into security for liquid working capital. The community based social capital thus becomes a collateralizing transformer of financial capital provided by MFIs into working capital, used in form of microloans by members of village banks. Viewed from another angle, the lack of credit in developing regions from the point of view of formal banking can be considered a lack of understanding of specificities of reality in development regions by formal banks, rather than underdevelopment: or lack of understanding of the nature of financial capital by traditional institutions and their incapacity to permeate existing cultural structures, collateralizable with the of local knowledge. Success of group lending is conditioned by a presence of social capital, being considered by Narayan (1999) as the agent leading to less imperfect information transfer and to a reduction of transactions costs. Social links among group borrowers not only increase ability to participate in loan and saving operations, but also lead to more efficient information flows between borrowers and lenders, reducing adverse selection as well as moral hazard and creating additional tools for enforcement of 
defaulted credits in environments without robust legal mechanisms. The classical theory of social integration as well as the sanctioning capacity of group rituals (Durkheim, 1984) possibly the explanation of why the motivation of borrowers is instrumental rather than consummatory. The financial system self-organizes inputs into dynamic economic activities allocating resources (Brock, 1991) and requires agents to master the pool of adequate information in order to form rational expectations, as assumed by neoclassicists, who however ignore the influence of a Knightianuncertainty. Seen from this point of view, the study proposes, on the top of a Bird in Hand, Affordable Loss, Lemonade, Pilot-in-the Plane and Patchwork Quilt principles to add another one, suited particularly to microfinance clientele, combining entrepreneurship with group subordination: the Musketeer Principle. This principle considers the individual bank debt as a structural element transmitting through individual compression the total weight of village bank debt structure to individual group members. In other words, village bank members need the capacity to embrace individual projects in a wider group project endeavour with limited information as well as imperfect foresight of future forcing them to continuously monitor as well as adapt to their group environment, steadily reconfirming the group dynamics, being both causal as well as effectual.

\section{The musketeer principle}

Market participants are provided limited information as well as imperfect foresight of future and must be continuously changing as well as learning from the evolving environment. In contrast to classical type of venture entrepreneurs or start-up entrepreneurs in developed economies, the microfinance entrepreneurs have a different profile. Besides being mostly a female focused entrepreneurship as $85 \%$ of the microfinance clientele form women, they are bound through a collective obligation which is the solidarity based village bank credit (Daley-Harris, 2007). This makes them share information as well as time-spatial conditions of their entrepreneurship and could be therefore considered as lose partners, with intentionally created partnerships with the aim to acquire external capital. In this respect they also differ from cooperativists, bound in a common project with distributed and not individual decision taking.

Village banks thus form a completely new entrepreneurship figure, which is to be studied from the point of view shared responsibility, power as well as effectuation. Units of socially homogenous groups are created in order to empower mechanisms of rule enforcement, enhance social capital in a different way than the social capital dotted to individual entrepreneurs. If we considered social capital as a societal web, the microfinance partnerships create islands of socially homogenous units formally bounded by credit and can be also expected to create platforms or integrators of information sharing, empowerment and culture distribution.

It is to be expected that the capacity of rule enforcement is higher in homogenous groups rather than heterogeneous groups, seen from the social point of view. Trust and homogeneity factors include religion, membership of the same cultural community, ethnic group, common neighbourhood, however not consanguinity as this factor is usually forbidden by microfinance practitioners. Social cohesion translates into better rule enforcement, ritual comprehension and thus more successful credit operations and better per monitoring, information transfer as well as success of microfinance operations not only focused on credit. The connectivity is thus to be expected the success factor for microfinance institutions leading. The connectivity is to be measured 
and this paper intends to lay basis for creation of a measurement methodology of microfinance cohesion which will in turn be able to predict the success of microfinance operation and which is based upon the Effectuation as well as Social Capital concept.In the context of microfinance social capital plays a very important role as it has very close and positive relations with empowerment of women which is one of the most important objectives of most microfinance programmes. Social and political empowerment which concentrate on 'power with' and 'power over' state that social capital created through network helps them to bring out social mobilization, build alliances and act as a collective force to bring out changes in gender based social structure.

It is assumed that social capital plays a very crucial role in social empowerment of women which can be viewed in terms of higher level of conscientization of women in enhancing awareness and knowledge, higher level of interactive activities leading to higher mobility, higher collective action and better decision making abilities and better social position in the family and neighbourhood. Nahapiete et al. (1998) and Adler et al. (2002) identify several benefits of presence of social capital, including facilitation of information access, influence, power and control helping people to start and finish project processes, ensuring solidarity as well as compliance, providing guidance for socialization and for more efficient social (commercial) behaviour. Social capital can be seen as an accumulation of obligations in a group, obeying reciprocity norms. Unlike in formal financial systems, the repayment obligation pressure thus stems not from legal norms nor normatives of society but from responsibilities derived from belonging to social structures, including its ritual component. Default risk is thus a function of the accepted norms derived from social capital. The threat of sanctions and ostracism based on community norms acts as a collateral, being higher in a smaller group than in state sponsored normative system, as shown by low default rates of MFIs, caused by frequent repayment model in a group setting (Armendariz and Morduch, 2000). The obligations are thus possible enforceable due to pre-existence of norms rather that value respect for joint liability than due to implementation of microfinance methodology. The pool of social capital is thus the most important tool for microfinance creditors, acting as the ultimate and superior financial meta-collateral. In other words, access to credit, permitting accumulation of capital in a situation of a low level of savings, owes its potential to social capital being to a large extent a result of cultural factors. This simple reasoning denudes the fact that social capital is an instrument of control, to which social cohesion is the ultimate result.

\section{Description of the musketeer principle}

Under the abovementioned perspective there are a number of assumptions of financial order that should describe the Musketeer Principle. If we consider the initial conditions of the model, the loan amounts $\left(\mathrm{L}_{\mathrm{i}}\right)$ for all members should be homogeneous $(\delta)$ to the maximum extent possible in terms of size and conditions, as low disparities make the group more coherent. Mathematically thought we get a starting constraint given by:

$$
l_{i} \leq \delta \text { and } \sum_{i} l_{i}=A_{T} \leq k \delta \text { with, } l_{i}, \delta \geq 0
$$

This initial condition can be extended to a system of ranks within the initial outline:

$$
\delta \leq l_{i} \leq \varepsilon \operatorname{and} k_{1} \delta \leq A_{T} \leq k_{2} \varepsilon
$$

Constraint (1) in respect to the condition (2) implies lower administrative costs and less likelihood of emergencies by potential conflicts of interest. However, the 
scheme (2) may be transformed by a discretization of three forms of loan: low (L), medium (M) and high (H), with three different points taken over the range from low to high respectively.

This variant can be interesting because it introduces a diversification which could cover certain capital differential for certain members of the village bank. In the next cycle of loans, it is understood that for a rating of a loan, all individuals must have paid off the loan on the initial condition. That condition thus directly introduces the Musketeer Principle, since the loan guarantee implies that all members are considered debtors for each loan of each of member of the group. Under that provision it is sufficient for the MFI to issue a single promissory note to the village bank, while individual promissory notes cause minimal risk reduction while operating against the Musketeer Principle.

To define the structure of the renewal of loans, quantitative evaluation models and risk are needed to reach a sufficient degree of systematization (applicable to each of the members). For this type of evaluation there are different methodologies, but it is important to summarize that there must be linear model for new loans in the following form:

$$
P_{t}=\varnothing\left(P_{t-1}, A_{s}, B_{p}, M_{a}\right)
$$

where $P_{t}$ equals the value of the previous loan; where $A_{s}$ is the amount saved; $B_{p}$ equals the repayment behaviour related to percentage of successfully repaid loans and $M_{A}$ is participation in weekly repayment meetings. With these type of qualifications, it is possible to enter different levels of new loans and establish the minimum to comply to avoid being excluded from the failure conditions. Regardless of the scheme which is chosen and the weights that affect the definition of the structure of the new loan, it is possible to enter a discrete renewal scheme to increase the quality of monitoring. The proposed valuation models repeated for different cycles can enabled understanding and consolidation of the flow and repayment capacity.

High, medium and low valuation model proposals:

High: $\mathrm{P}_{\mathrm{t}}=\mathrm{P}_{\mathrm{t}-1}+\frac{2}{3} * \mathrm{P}_{\mathrm{t}-1}$ Medium. $\mathrm{P}_{\mathrm{t}}=\mathrm{P}_{\mathrm{t}-1}+\frac{1}{2} * \mathrm{P}_{\mathrm{t}-1}$ Low. $\mathrm{P}_{\mathrm{t}}=\mathrm{P}_{\mathrm{t}-1}+\frac{1}{3} * \mathrm{P}_{\mathrm{t}-1}$

It is implied that the breaches of repayment must be combined with penalty schemes to alert members of the mechanisms of exclusion. However, the scheme would build four-dimensional arrays of multiple responses based on the following probabilities. $p_{B}$ : payment probability

$p_{M}$ : weekly encounter probability

$p_{E}:$ default probability

$p_{s}$ : saving probability

In the case of the likelihood of saving this can be calculated as the savings accrued through period ( $\mathrm{t}-1)$ divided by loans made in the period $(\mathrm{t})$. Starting odds scheme can be constructed in a matrix response containing multiple columns and variable payments, savings, assistance and penalties, using in the first step a Bernoulli scheme with the resulting matrix containing 0 and 1 . This rating is as far as quality satisfaction levels for each of the columns are established. A major advantage of this approach is that for each cycle can define a measure of the strength of the Musketeer Principle or "porosity" of the village bank given by:

$$
\text { por }=1-\sum_{i j} a_{i j} / T
$$


where $\mathrm{T}$ is the number of individuals present in the credit cycle. A high Musketeer Principle adherence (low porosity) involves a lower risk of village bank loan, due to higher level of social capital of the group members.

\section{Data}

This study will perform a test of data of a similar scope collected in identical data techniques from microfinance clientele in four different countries: in Sierra Leone (Ing. Sheku Mansaray, CULS Ph.D. student, was responsible for data collection) in the Bari and Niawa Chiefdom (Mansaray et al., 2015), in Indonesia in Toba Samosir in Northern Sumatra (Ing. Libuše Valešová, CULS Ph.D. student, was in charge of the data collection), in Turkey in the outskirts of Ankara, in collaboration with Turkish microfinance institution TGMP (Research team consisted of Ing. AlenaNeradová, Dipl.-Kfm. Tomáš Hes, Doc. Karel Srnec) and in Afghanistan, in rural and urban area in the province of Kabul Afghanistan (Shamshad Zadran, CULS masters student, was responsible for data collection)(Zadran, 2015), in order to find out a potential difference in relation to the Musketeer principle in selected countries. In Sierra Leone, AMNet MFI with 800 total of clients and non-clients is 800 was subject to data collection. The non-microfinance clients will respond to a set of twenty questions on a questionnaire similar to, but slightly different from the clients' questions. The target was 400 respondents from the microfinance zone and 400 hundred from the non-microfinance zone. In Indonesia, data were gathered in 2012 and 2013 in North Sumatra province, within Analysis of Household Livelihood Strategies and Food Security Analysis.

A stratified approach with quota sampling was used to collect data among rural households, in two districts of the Province, including Toba Samosir Regency and Samosir Regency, in total with 169 respondents. In Turkey, data were collected in 2012, in cooperation with Turkish microfinance institution TGMP and SESRIC, subsidiary organ of the Organization of Islamic Cooperation (OIC), in a survey project focused on the microfinance clientele in the suburban outskirts of Ankara. The survey was completed by 117 active clients, belonging to the stable core of TGMP portfolio. In Afghanistan, data was collected in 2014 in rural and urban area in the province of Kabul in Afghanistan. Cluster sampling methods was used for data collecting, in in 5 districts (Dih Sabz, Surobi, Bagrami, Paghman and Chahar Asyab), and Kabul city which is pointed in the map of Kabul province. Responses were characterised in their specific answer categories that correspond to the five selected categories of Effectuation Theory: Bird in Hand, Affordable Loss, Pilot-In-The-Plane, Patchwork Quilt and Musketeer Principle. Answers were summed up and structured into categories that corresponded to these five principles. The Lemonade Principle was omitted, as it corresponds to the capacity of the entrepreneur to respond to situations of surprise, that were rather difficult to assign to the responses in questionnaires in all four countries.

Table 1. Collected data descriptive statistics of effectuation principles

\begin{tabular}{|l|l|l|l|l|l|}
\hline & Bird in Hand & $\begin{array}{l}\text { Affordable } \\
\text { Loss }\end{array}$ & $\begin{array}{l}\text { Pilot In The } \\
\text { Plane }\end{array}$ & $\begin{array}{l}\text { Patchwork } \\
\text { Quilt }\end{array}$ & $\begin{array}{l}\text { Musketeer } \\
\text { Principle }\end{array}$ \\
\hline Average & 2,27 & 1,22 & 2,33 & 1,25 & 3,34 \\
\hline Standard Err. & 0,06 & 0,02 & 0,07 & 0,03 & 0,09 \\
\hline Median & 2,00 & 1,00 & 2,00 & 1,00 & 3,00 \\
\hline
\end{tabular}




\begin{tabular}{|l|l|l|l|l|l|} 
Standard Dev. & 1,02 & 0,41 & 1,36 & 0,55 & 1,73 \\
\hline Variance & 1,04 & 0,17 & 1,86 & 0,30 & 2,99 \\
\hline Kurtosis & 1,88 & $-0,14$ & 0,61 & $-0,38$ & 1,13 \\
\hline Asymmetry & 0,77 & 1,36 & 0,69 & 0,05 & 0,67 \\
\hline
\end{tabular}

Source: Authors' own research.

\section{Data processing through PCA}

The method of principal components analysis (PCA) was chosen in order to transform numbers of correlated variables into sets of uncorrelated variables, denominated as principal components, with the purpose of derivation of a set of new variables, being the linear combination of the original ones, with the ultimate goal to reduce the data dimensionality. Low dimension based linear combinations of variables can be more easily interpreted and served in more complex analysis, giving different weights to different variables (Abdi et al., 2010). The reduction of the set of $p$ variables is conceived in order to create sets of $m$ superordinate, underlying dimensions, inferred from correlational relationships among $p$ variables, while every factor was weighted a sum of the variables, with the $i^{\text {th }}$ factor thus being described in the multivariate data matrix as below (Abdi et al., 2010):

$$
\mathrm{PX}=\left(\begin{array}{llll}
\mathrm{Px}_{1} & \mathrm{Px}_{2} & \cdots & \mathrm{Px}_{\mathrm{n}}
\end{array}\right)=\left(\begin{array}{cccc}
\mathrm{p}_{1} \cdot \mathrm{x}_{1} & \mathrm{p}_{1} \cdot \mathrm{x}_{2} & \cdots & \mathrm{p}_{1} \cdot \mathrm{x}_{\mathrm{n}} \\
\mathrm{p}_{2} \cdot \mathrm{x}_{1} & \mathrm{p}_{2} \cdot \mathrm{x}_{2} & \cdots & \mathrm{p}_{2} \cdot \mathrm{x}_{\mathrm{n}} \\
\vdots & \vdots & \ddots & \vdots \\
\mathrm{pm}_{\mathrm{m}} \cdot \mathrm{x}_{1} & \mathrm{p}_{\mathrm{m}} \cdot \mathrm{x}_{2} & \cdots & \mathrm{p}_{\mathrm{m}} \cdot \mathrm{x}_{\mathrm{n}}
\end{array}\right)=\mathrm{Y}
$$

The multivariate data matrix thanks to linear combinations with the large variances, converts observations into values of linearly uncorrelated variables denominated as principal components.

Table 2. Eigenanalysis of the correlation matrix

\begin{tabular}{|l|lccc|}
\hline Effectuation Principle & Component & Eigenvalue & Proportion & Cumulative \\
\hline Bird in Hand & 1 & 1.6215 & 0.3243 & 0.3243 \\
\hline Affordable Loss & 2 & 1.3640 & 0.2728 & 0.5971 \\
\hline Pilot-In-The-Plane & 3 & 0.9796 & 0.1959 & 0.7930 \\
\hline Patchwork Quilt & 4 & 0.7430 & 0.1486 & 0.9416 \\
\hline Musketeer Principle & 5 & 0.2919 & 0.0584 & 1.0000 \\
\hline
\end{tabular}

Source: Authors' own research.

Table 3. Eigenvectors

\begin{tabular}{|l|rrrrr|}
\hline Effectuation Principle & PC1 & PC2 & PC3 & PC4 & PC5 \\
\hline Bird in Hand & -0.108 & -0.264 & 0.938 & -0.169 & 0.102 \\
\hline Affordable Loss & 0.298 & -0.515 & -0.251 & -0.763 & 0.032 \\
\hline Pilot-In-The-Plane & -0.701 & -0.146 & -0.208 & -0.079 & 0.662 \\
\hline Patchwork Quilt & -0.404 & -0.644 & -0.113 & 0.290 & -0.570 \\
\hline Musketeer Principle & -0.496 & 0.479 & 0.031 & -0.546 & -0.475 \\
\hline
\end{tabular}

Source: Authors' own research. 
Table 4. Correlation matrix

\begin{tabular}{|l|l|l|l|l|l|}
\hline Nd & $\begin{array}{l}\text { Affordabl } \\
\text { e Loss }\end{array}$ & $\begin{array}{l}\text { Pilot-In- } \\
\text { The-Plane }\end{array}$ & $\begin{array}{l}\text { Patchwor } \\
\text { k Quilt }\end{array}$ & $\begin{array}{l}\text { Musketeer } \\
\text { Principle }\end{array}$ & \\
\hline 1.0000 & -0.0012 & 0.0140 & 0.1448 & -0.0028 & Bird in Hand \\
\hline & 1.0000 & -0.1338 & 0.1149 & -0.2780 & Affordable Loss \\
\hline & & 1.0000 & 0.4828 & 0.4018 & Pilot-In-The-Plane \\
\hline & & & 1.0000 & -0.1388 & Patchwork Quilt \\
\hline & & & & 1.0000 & Musketeer Principle \\
\hline
\end{tabular}

Source: Authors' own research.

\section{Results and discussion}

The fact there are two subgroups of correlations in the correlation matrix above 0.3 (Tabachnick et al., 2001), with the highest correlation reaching only 0.48 (E and D) and 0.40 ( $F$ and $\mathrm{D}$ ) illustrates that the 5 principles of effectuation under examination seem to be in general rather uncorrelated. The eigenvectors, in relation to the effectuation principles seem to hint at the fact that principles of Bird in Hand $(32,43 \%$ explained), Affordable Loss (27,28\% explained) and Pilot-In-The-Plane (19,59\%), while Patchwork Quilt (14,86\% explained) and Musketeer principle (5,84\% explained) seem to be rather less important for the explanation of the behaviour of village bank groups in the examined samples.

Graphic comparison of the four countries seems to show that the chosen principles do not provide us with important clues, with one difference of Indonesia, which shows important differences to Afghanistan, Sierra Leone and Turkey especially when Bird in Hand, as well as Affordable Loss and Musketeer principles are concerned. It can be stated therefore that Indonesian microfinance market seems to show different values in perception of risk as well as village bank cohesion than the markets in the other countries selected and therefore this seems to be worth of analysis in future studies.

\section{Conclusion}

As Kuhn points out, paradigm shifts lay not so much in the invention or in the discovery of new knowledge as in new ways of looking at the things that are considered to be well known, while it is the very essence of human cognition to absorb new information into well-understood patterns (Wiltbank et al., 2010). Effectuation theory, due to its relative youth is therefore still to pass the test of universality and there may be adjustments on the way to be accepted, such as the Musketeer Principle, which may be a required adaptation of the effectuation theory for development microfinance markets, and especially in the use of village banking. This proposed adaptation takes into account the fact that microenterpreneurs grouped in village bank need apart from entrepreneurial risk structuration capacity also the ability to work in groups and manage social capital, sharing debt with peer village bank members, which is a combination necessary for village bank loan edification as well as a successful sustenance of village bank loans.

As revealed by the comparison between the four chosen microfinance markets, there exist visible differences in the nature of thinking of microenterpreneurs in relation to Musketeer principle. Even if less important in explaining the effectuation in village banking than the four principles described, it can be therefore concluded, that the logics of village bank members and microfinance practitioners, which requires a combination 
of a groupwise activity attributes based on democratic decision taking with the entrepreneurial spirit able to structure non-predictive environments, in certain countries shows signs of different values pointing at a future direction to be investigated.

\section{Funding acknowledgement}

This research was financially supported by the Faculty of Tropical AgriSciences, project number 20165011.

\section{References}

Abdi, H. and Williams, L.J. (2010), "Principal component analysis", Wiley Interdisciplinary Reviews: Computational Statistics, Vol. 2, pp. 433-459.

Armendáriz, B. and Morduch, J. (2000), "Microfinance beyond group lending", The Economics of Transition, Vol. 8, No. 2, pp. 401-420.

Becker, G. (1993), Human capital: A theoretical and empirical analysis, with special reference to education, 3rd ed., University of Chicago Press, Chicago.

Bowles, S. and Gintis, H., (2002), "Social capital and community governance", The Economic Journal, Vol. 112, No. 483, pp. 419-436.

Brock, W., Lakonishok, J. and LeBaron, B. (2004), "Simple technical trading rules and stochastick properties of stock returns", The Journal of Finance, Vol. 47, pp. 17311764.

Chandler, A., DeTienne, D., McKelvie, A. and Mumford, T. (2012), "Causation and effectuation processes: A validation study", Journal of Business Venturing, Vol. 26, No. 11, pp. 375-390.

Coleman, J. (1988), "Social capital in the creation of human capital”, American Journal of Sociology, Vol. 94, pp. S95-S120.

Daley-Harris, S. (2007), Microcredit Summit Campaign Report 2007, Results Educational Fund, Washington.

Durkheim, E. (1976), The division of labor in society, Simon and Schuster.

Hes, T. and Polednakova, A. (2013), "Correction of the claim for microfinance market of 1.5 billion clients", International Letters of Social and Humanistic Sciences, Vol. 2, pp. 18-31.

International Labour Organisation (ILO) (2002), Women and men in the informal economy: A statistical picture, ILO, Geneva.

Grootaert, C. and Bastelaer, T. (2001), "Understanding and measuring social capital", World Bank Group, Social Capital Initiative, Working paper 24.

Isham, J., Kelly, T., Ramaswamy, S., (2002), "Social capital and well-being in developing countries: an introduction", In Isham, J., Kelly, T., Ramaswamy, S. (Eds.), Social capital and economic development: Well-being in developing countries, Edward Elgar, Northampton, pp. 3-17.

Knight, F. (1921), Risk, uncertainty and profit, Houghton Mifflin, New York.

Mansaray, S., Maitah, M., Hes, T. and Malec, K. (2015), "Microfinance in Southeastern Sierra Leone", Research Journal of Business Management, Vol. 9, No. 4.

March, J.G. (1982), "The technology of foolishness", In March J.G. and Olsen J.P (Eds.), Ambiguity and choice in organizations, Universitetsforlaget, Bergen. 
Nahapiet, J. and Sumantra, G. (1998), "Social capital, intellectual capital and the organizational advantage", The Academy of Management Review, Vol. 23, No. 2, pp. 242-266.

Narayan, D. (1999), "Centes and sociability: household income and social capital in rural Tanzania”. World Bank Policy Research Papers November 1999.

Putnam, R., Leonardi, R. and Nanetti, R. (1993), Making democracy work: Civic traditions in modern Italy. Princeton University Press, Princeton.

Roy, D. and Ghosh, K. (2010), "A proposed model of a microcredit institution: break-even analysis, borrowing group credit worthiness and risk analysis", 6 th $^{\text {th }}$ IMT Conference on Mathematics, Statistics and Its Applications, Tunku Abdul Rahman, Malaysia.

Sarasvathy, S. (2001), "Causation and effectuation: Toward a theoretical shift from economic inevitability to entrepreneurial contingency", The Academy of Management Review, Vol. 26, No. 2, pp. 243-263.

Schumpeter, P. (1976), Capitalism, socialism, and democracy, Allen and Unwin, London.

Seibel, H.D. (2005), "Islamic microfinance in Indonesia". University of Cologne, Development Research Center, available on: www.ruralfinance.org.

Tabachnick, B.G. and Fidell, L.S. (2013), Using multivariate statistics, 6th ed. Pearson, Boston.

Weick, K. (1979), The social psychology of organizing, $2^{\text {nd }}$ ed., McGraw Hill, New York.

Wiltbank, R. and Sarasvathy, S. (2010), "What effectuation is not: Further development of an alternative to rational choice". Academy of Management Conference.

Yunus, M. (1999), Banker to the poor, Public Affairs, New York.

Zadran, S. (2015), "Islamic microfinance in Afghanistan", Master's thesis, Faculty of Tropical AgriSciences, Czech University of Life Sciences Prague.

\section{Appendix}
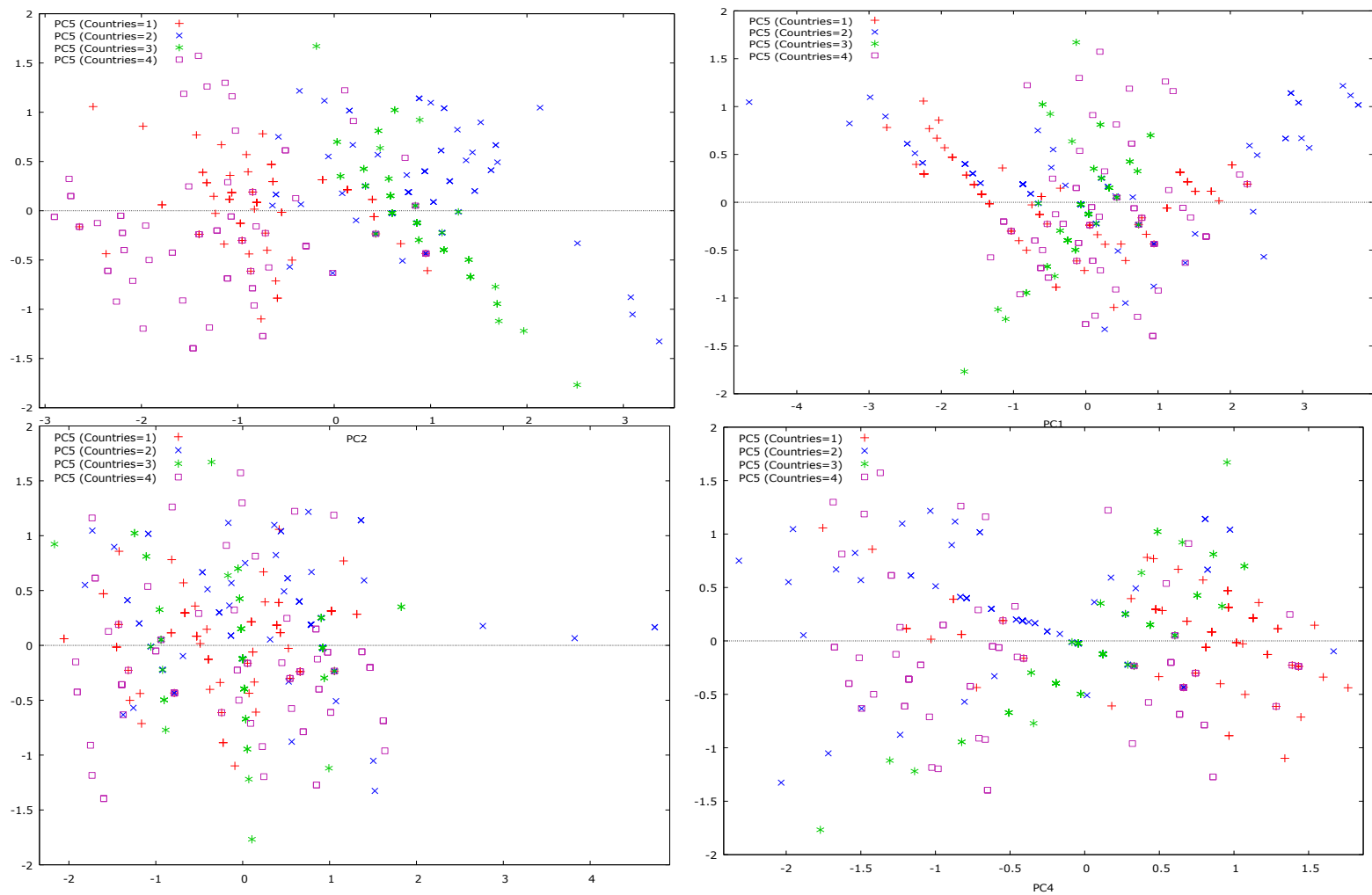

Vol. 12, No. 1, Spring, pp. $3^{\mathrm{pc}}$-48, ISSN 1842-0206 | Management \& Marketing. Challenges for the Knowledge Society 